\title{
Fertility and Offspring Sex Ratio in Grade Stations Occupants: Occupational Exposure to Long Term Strong Electromagnetic Fields
}

\author{
Ghulam Nabi ${ }^{1, *}$, Imran Ali Khan ${ }^{2}$, Sardar $\mathrm{Ali}^{3}$, Yousaf Khan ${ }^{4}$, Sami Ullah \\ ${ }^{1}$ Department of Animal Sciences, Lab of Reproductive Neuroendocrinology, Quaid-i-Azam University, Pakistan \\ ${ }^{2}$ Department of Physics, Quaid-i-Azam University, Pakistan \\ ${ }^{3}$ Department of Microbiology, Kohat University of Science and Technology, Pakistan \\ ${ }^{4}$ Lab Technician, Khyber Medical University, Pakistan \\ ${ }^{5}$ Department of Zoology, Islamia College University, Pakistan
}

Copyright (C) 2015 Horizon Research Publishing All rights reserved.

\begin{abstract}
The objectives of this study were to investigate the effects of long term strong electromagnetic field on fertility and offspring sex ratio in grade stations occupants. Fifty grade stations $(132 \mathrm{kV}$ and $500 \mathrm{kV})$ occupants and fifty control peoples were recruited randomly from district Dir, Swat and Peshawar (Pakistan). A special questionnaire was filled from all study participants about, age, job history, exposure time, protective clothing, addictions, fertility and number and sex of children. It was found that in exposed group, infertility both primary $(\mathrm{n}=5 / 50)$ and secondary $(n=5 / 50)$ was common as compared to control group. Similarly the numbers of female children were significantly $(<0.0001)$ higher while the numbers of male children were significantly $(<0.0001)$ lowered in exposed group as compared to control group. In conclusion, long term strong electromagnetic field exposure decreases fertility and alters offspring sex ratio.
\end{abstract}

Keywords Infertility, Electromagnetic Field, Ratio

\section{Introduction}

In many countries during recent decades fertility has been decreased [1-2]. Numerous behavioral and social alterations, in addition to biological mechanism lead to fertility problems. Several studies reported that in the past half century, semen quality has been reduced compromising normal fertility [3-4]. For reduction of semen quality, a lot of occupational and environmental exposures are suggested as risk factors but, some of them are consistently identified. Two of them are non-ionizing magnetic field, emitted by electric and electronic equipment's and electric field $[1,5,6]$. Electromagnetic field emitted from electronic equipment negatively affects reproductive health in Royal Norwegian
Navy [7]. It has been investigated that persistent exposure to magnetic fields has ill effects on sperm concentration [8], sperm motility [9], [10], and decreases sex ratio among fathers exposed to magnetic and electric fields [11-12]. Irgents et al. found that infertility was very common in men, occupationally exposed to electromagnetic field (worked as electrician, cook and welder) by decreasing semen quality [13]. Similarly electromagnetic field exposure decreases offspring sex ratio, with fewer boys borne [11-12] but, these studies are small and only one study has shown significant effects [14]. In animal study it has been found that magnetic field exposure decreased the volume of seminiferous tubules, causes testicular degeneration and pathological lesions. It also compromises spermatogenesis and spermiations. The sertoli cells worsen when animals are exposed to magnetic field of 50d however, no changes in plasma testosterone were observed in control and treated group when exposed to 15, 30 and $60 \mathrm{~d}$. Sperm mitochondria lose cristae and are abnormally organized in exposed group [15]. Similarly electric field exposure in female rats significantly decreases fertility and increase the incidence of malformed fetuses [16]. Men are exposed to low frequency electromagnetic field emitted from natural sources such as sun, earth and human body but, from the last 120 years use of electricity in industries and homes for light, cooking, heat and power has brought about far greater and increasing exposures to electric and magnetic fields. Exposures to these devices are now a part of the modern life [17-18].

In Pakistan, especially in Khyber Pakhtunkhwa, the awareness about hazardous effects of strong electromagnetic field exposure is totally lacking. The grade stations occupants in Khyber Pakhtunkhwa are exposed to strong electromagnetic field for more than 8 hours each day. They even are not using any special protective clothing. To analyze the hazardous effects of strong electromagnetic field, regarding fertility and offspring sex ratio 50 workers in the 
grade stations (132 kV and $500 \mathrm{kV})$ and 50 peoples (control) were interview via a standard questionnaire.

\section{Subjects and Methods}

\subsection{Study Area}

Study participants were recruited randomly from the district Dir, Swat and Peshawar.

\subsection{Inform Consent}

Before starting the study, informed consents were signed from all the study participants. Their informations were strictly used for research purpose.

\subsection{Questionnaire}

A special questionnaire was designed. It includes information about their age, occupational exposure time, history of job, fertility, addiction, and number and sex of children.

\subsection{Study Design}

Two groups were made; control and exposed. Each group contained 50 participants. All of them were married. Their age ranged from 30 to 45 years. Control group were not exposed to such strong electromagnetic field of the grade stations. All of them were healthy.

\subsection{Exclusion criteria}

Participants using marijuana, cigarette, medicines and extremely ill were excluded from the study.

\subsection{Statistics}

Graph pad prism, version 6.03 (Graph Pad Software Inc., San Diego, CA, USA) was used to analyze the difference (Mean $\pm \mathrm{SD}$ ) of children sex ratio in both groups by using student un-paired t test. A value of $p<0.05$ was considered statistically significant

\section{Results}

Table 1. History of study population

\begin{tabular}{cccccc}
\hline \multirow{2}{*}{ Groups } & $\begin{array}{c}\text { Job } \\
\text { History }\end{array}$ & $\begin{array}{c}\text { Exposure } \\
\text { To EMF }\end{array}$ & $\begin{array}{c}\text { Protective } \\
\text { coverings }\end{array}$ & Addictions & Infertility \\
\hline \multirow{2}{*}{ Exposed } & $\geq 10$ & $\geq 8$ hrs. & Nill & Nill & PI $^{*} 5 / 50$ \\
& years & SI $5 / 50$ \\
Control & variable & Nill & Nill & Nill & Nill \\
\hline
\end{tabular}

$\mathrm{EMF}^{*}=$ Electromagnetic Field, $\mathrm{PI}^{*}=$ Primary Infertility,

$\mathrm{SI}^{*}=$ Secondary Infertility
Table 2. Children sex ratio in study population

\begin{tabular}{|c|c|c|c|c|}
\hline Parameters & $\begin{array}{c}\text { Control } \\
\text { Mean } \pm \text { SD }\end{array}$ & $\begin{array}{c}\text { Exposed } \\
\text { Mean } \pm \text { SD }\end{array}$ & 95\% C.I* & $P$ value \\
\hline $\begin{array}{l}\text { Female } \\
\text { children }\end{array}$ & $2.36 \pm 1.41$ & $3.68 \pm 1.74$ & $\begin{array}{c}-1.949 \text { to } \\
-0.690\end{array}$ & $\begin{array}{c}<0.0001 \\
(* * * *)\end{array}$ \\
\hline $\begin{array}{c}\text { Male } \\
\text { children }\end{array}$ & $3.94 \pm 1.49$ & $2.06 \pm 1.58$ & $\begin{array}{c}-2.490 \text { to } \\
-1.270\end{array}$ & $\begin{array}{c}<0.0001 \\
(* * * *)\end{array}$ \\
\hline
\end{tabular}

$\mathrm{CI}^{*}=$ Confidence Intervals

In exposed group both primary $(\mathrm{n}=5)$ and secondary $(\mathrm{n}=5)$ infertility were more common as compared to control group. The numbers of female children in exposed group were significantly higher but the numbers of male children were significantly lower when compared with control group. The details of the history and results are summarized in Table 1 and Table 2.

\section{Discussion}

In the present study we investigated the effects of chronic and strong electromagnetic field exposure in grade stations occupants and found that, persistent exposure to strong electromagnetic field decreases fertility and alter offspring sex ratio (having more daughters than boys). Our results are in agreements with the findings of Baste et al. who found that when military men employed in the Royal Norwegian Navy get closed exposure to electromagnetic fields, infertility in these men increases. The degree of childlessness depends on the exposure time and distance from the electromagnetic field. Those fathers whose are exposed to strong electromagnetic field, the ratio of boys to girls at birth decreases significantly [19]. Similarly, exposure to low electric voltage decreases sperm motility and velocity but exposure to high electric voltage (more than $80 \mathrm{~V}$ ), sperm completely stop moving in the sperm counting chamber [20]. Persistent exposure to electromagnetic fields can causes perinatal mortality, prenatal growth retardations, spontaneous abortions, congenital anomalies, decrease male/female birth ratio and male infertility. These abnormalities were reported in peoples using video display terminals (VDTs), home heating devices, bed heating devices and from employment in electric occupations [21]. Certain peoples such as electrician, welders, substation operators, linesmen, railway station workers, radio and television repairs men and telephonists are exposed to electromagnetic fields for a long time as compared to other peoples. As compared to linesmen who are always working with power lines, welders are more exposed to electromagnetic fields. Similarly peoples in other occupations may also be exposed to electromagnetic fields, for example peoples in the proximity of VDTs [22]. It has been reported that there is a greater risk of congenital anomalies and miscarriage in families whose husbands are working in electric power industries [23]. In Swedish study a significant difference was found in utility substation workers and control group about family size and fertility [24]. Adult female Spague-Dawley rats were exposed to a $50 \mathrm{~Hz}$ for a 
period of 18 weeks. Serum levels of reproductive hormones such as, estrogens, progesterone, follicle stimulating hormones (FSH) and luteinizing hormones (LH) were analyzed before, after and during exposure to electromagnetic fields. After six weeks of exposure, LH and FSH reduction was significant. Only on week six, FSH levels were affected but LH remained affected during at twelve and eighteen week. Similarly progesterone and estrogen levels were significantly reduced during 12 week of exposure. All these results indicate that, electromagnetic exposure has ill effects on fertility by decreasing the concentrations of hormones that are essentials for reproductions [25].

Magnetic field exposure can causes dysfunctions of pineal glands by negatively affecting the synthesis and secretion of melatonin. This melatonin has a role in the regulation of reproductive hormones. So any negative alterations in the melatonin can cause ill effects on the reproductive hormones [26-27]. In the brain, pineal gland is suggested as magneto sensor because, exposure of experimental animals to magnetic field alter the firing rate of pineal gland cells, thus inhibiting the secretions of melatonin [28]. Several studies have reported that long term electromagnetic field exposure disrupts male fertility by: reducing sperm motility, count and spermatogenesis; hazardous effects on semen quality, damage to acrosomes and plasma membranes; compromising sperm ability to penetrate oocyte; altering spermatozoal calcium homeostasis; inducing damage to testicular tissues; inducing delay development of testicular tissues; reduced testicular biopsy score; alterations in the intertubular tissues of testes; germ cells degenerations; cytotoxicity of spermatogonia and inductions of germ cells apoptosis [29-31]. Reduction in testicular weight has been reported in animals when exposed to a magnetic field of 30 and $60 \mathrm{~d}$, suggesting impaired spermatogenesis because testicular weight has a positive correlation with spermatogenesis and sperm function [32] as well as indicate a loss of germ cells [33]. Similarly a reduction in the volume of seminiferous tubules and gonadosomatic index is reported in animals exposed to a magnetic field of $60 \mathrm{~d}$, indicating impaired spermatogenesis [34].

\section{Conclusions}

In conclusion, grade stations occupants are exposed to strong electromagnetic field each day for years. This exposure has negative effects on fertility and also alters offspring sex ratio (having more daughters as compared to boys). Further studies are needed to investigate the exact molecular mechanism for this altered sex ratio and infertility.

\section{REFERENCES}

[1] NE. Skakkebaek, N. Jorgensen, ME. Main, J. Toppari, H. Leffers, A. Juul, TK. Jenson, NE. Skakkebaek. Is human fecundity declining? Int J Androl, 29, 2-11, 2006.
[2] M. Sallmen, CR. Weinberg, DD. Baird, ML. Lindbohm, AJ. Wilcox. Has human fertility declined over time? Why we may never know. Epidemiology, 16, 494-9, 2005.

[3] E. Carlsen, A. Giwercman, N. Keiding, NE. Skakkebaek. Evidence for decreasing quality of semen during past 50 years. BMJ, 305, 609-13, 1992.

[4] AG. Andersen, TK. Jensen, E. Carlsen, E. Jorgensen, AM. Andersson, T. Krarup, N. Keiding, NE. Skakkebaek. High frequency of sub-optimal semen quality in an unselected population of young men. Hum Reprod, 15, 366-72, 2000.

[5] JP. Bonde, Environmental fertility research at the turn of the century. Scand J Work Environ Health. 25, 529-36, 1999.

[6] A. Ahlbom, A. Green, L. Kheifets, D. Savitz, A. Swerdlow. Epidemiology of health effects of radiofrequency exposure. Environ Health Perspect, 112(17), 1741-54, 2004.

[7] N. Mageroy, OJ. Mollerlokken, T. Riise, V. Koefoed, BE. Moen. A higher risk of congenital anomalies in the offspring of personnel who served aboard a Norwegian missile torpedo boat. Occup Environ Med, 63, 92-7, 2006.

[8] SJ. Kilgallon, LW. Simmons. Image content influences men's semen quality. Biol Lett, 1, 253-5, 2005.

[9] O. Erogul, E. Oztas, I. Yildirim. Effects of electromagnetic radiation from a cellular phone on human sperm motility: an in vitro study. Arch Med Res, 37, 840-3, 2006.

[10] I. Fejes, Z. Zavaczki, J. Szollosi. Is there a relationship between cell phone use and semen quality? Arch Androl, 51, 385-93, 2005.

[11] B. Knave. Long-term exposure to electric-fields - cross-sectional epidemiologic investigation of occupationally exposed workers in high-voltage substations. Scand J Work Environ Health, 5, 115-25, 1979.

[12] M. Saadat. Offspring sex ratio in men exposed to electromagnetic field. J Epidemiol Community Health, $59,339,2005$.

[13] A. Irgens, K. Kruger, M. Ulstein. The effect of male occupational exposure in infertile couples in Norway. $\mathrm{J}$ Occup Environ Med, 41, 1116-20, 1999.

[14] A. Mubarak. Does high voltage electricity have an effect on the sex distribution of offspring? Hum Reprod, 11, 230-1, 1996.

[15] BM. Tenorio, BM. Ferreira Filho, GC. Jimenez, RN. de Morais, CA. Peixoto, A. Nogueira Rde, VA. da Silva Junior. Extremely low-frequency magnetic fields can impair spermatogenesis recovery after reversible testicular damage induced by heat. Electromagn Biol Med, 33(2),139-146, 2014.

[16] DN. Rommereim, WT. Kaune, RL. Buschbom, RD. Phillips, MR. Sikov. Reproduction and development in rats chronologically exposed to $60-\mathrm{Hz}$ electric field. Bioelectromagnelics, 8, 243- 258, 1987.

[17] JD. Jackson. Are the stray $60-\mathrm{Hz}$ electromagnetic fields associated with distribution and use of electric power a significant cause of cancer? Proc Natl Acad Sci USA, 89, 3508-3510, 1992.

[18] J. Swanson. Long-term variations in the exposure of the population of England and Wales to power-frequency 
magnetic fields. J Radiol Prot, 16, 287-301, 1996.

[19] V. Baste, T. Riise, BE. Moen. Radiofrequency electromagnetic fields; male infertility and sex ratio of offspring. Eur J Epidemiol, 23 (5), 369-77, 2008.

[20] S. Kazuo, K.Yuzo, H. Masahiko. Direct and indirect effects of electrical stimulation on the motility of human sperm. International journal of urology, 6, 196-99, 1999.

[21] MS. Gary. Adverse Human Reproductive Outcomes and Electromagnetic Fields: A Brief Summary of the Epidemiologic Literature. Bioelectromagnetics Supplement 5, 5-18, 2001.

[22] B. Knav. Electric and magnetic fields and health outcomes - an overview. Scand J Work Environ Health, 20, 78-89, 1994.

[23] S. Nordstrom, E. Birke, L. Gustafsson. Reproductive hazards among workers at high-voltage substations. Bio electromagnetics, 4, 91-10I, 1983.

[24] M. Bauchinger, R. Hauf, E. Schmid, I. Dresp. Analysis of structural chromosome changes and SCE after occupational long-term exposure to electric and magnetic fields from 380 kV-systems. Radiat Environ Biophys, 19, 235-8, 1981.

[25] AA. Moh'D. Influence of $50 \mathrm{~Hz}$ Magnetic Field on Sex Hormones and Body, Uterine, and Ovarian Weights of Adult Female Rats. Electromagnetic Biology and Medicine, 27, 155-163, 2008.

[26] R. Stevens. Electric power use and breast cancer: a hypothesis. Amer. J. Epidemiol, 125, 556-561, 1987.
[27] B. Wilson, RG. Stevens, LE. Anderson. Mini review: neuroendocrine mediate effects of electromagnetic-field exposure: possible role of the pineal gland. Life Sci, 45,1319-1332, 1989.

[28] M. Mevissen, A. Lerchl. Exposure of DMBA-treated female rats in a $50-\mathrm{Hz}, 50$ micro Tesla magnetic fields: effects on mammary tumor growth, melatonin levels, and $\mathrm{T}$ lymphocyte activation. Carcinogenesis, 17, 903-910, 1996.

[29] BM. Tenorio, GC. Jimenez, RN. Morais. Testicular development evaluation in rats exposed to $60 \mathrm{~Hz}$ and $1 \mathrm{mT}$ electromagnetic field. J. Appl. Toxicol, 31, 223-230, 2011.

[30] BM. Tenorio, GC. Jimenez, RN. Morais. Evaluation of testicular degeneration induced by low-frequency electromagnetic fields. J. Appl. Toxicol, 32, 210-218, 2012.

[31] DK. Li, B. Yan, Z. Li. Exposure to magnetic fields and the risk of poor sperm quality. Reprod. Toxicol, 29, 86-92, 2010.

[32] LD. Russel, RA. Ettlin, AP. Sinha Hikim. Mammalian spermatogenesis Histological and Histopathological Evaluation of the Testis" Bolesta: Cache River Press, 1-40, 1990.

[33] LL. Lanning, DM. Creasy, RE. Chapin. Recommended approaches for the evaluation of testicular and epididymal toxicity. Toxicol. Pathol. 30, 507-520, 2002.

[34] L. Franc,a, R. Avelar, GF. Almeida. Spermatogenesis and sperm transit through the epididymis in mammals with emphasis on pigs. Theriogenology, 63, 300-318, 2005. 